\title{
ABORIGINAL MAIZE CULTURE AS A TYPICAL CULTURE-COMPLEX
}

\author{
CLARK WISSLER \\ Curator of Anthropology, American Museum of Natural History, New York City
}

In maize culture as practiced by American farmers we have a fine example of a borrowed culture trait. It should be especially interesting to anthropologists and historians, since it is one of the few cases of culture transmission from a lower to a higher form of civilization concerning which we have much in the way of historical data. As everyone knows, maize was found in cultivation among the Indian tribes of our Atlantic seaboard and the Gulf coast, and was carried to the Old World by the very first explorers, where its use developed and spread with great rapidity. Familiarity with the cultures of these Indian tribes reveals a large culturecomplex based upon the production of this highly original New World food.

To set the case before the reader a brief enumeration of the elements making up this complex may be necessary. Naturally, the fundamental concept is the propagation of maize which embraces the related processes of preparing the soil, planting the grain, protecting the crop, gathering the ears, and preserving the seed. Each of these is a fixed procedure and must be followed in a definite order. While this is in itself a respectable complex, it is but the nucleus. The food production processes are numerous: maize was eaten green, hulled, and ground, with various forms for each. Mixed dishes of maize with beans, squash, or meat were prepared according to definite recipes. Looking in another direction, we find numerous religious ceremonies and social observances definitely associated with maize. Perhaps we have gone far enough to reveal the general characteristics of the maizecomplex in the cultures of our North American Indian tribes, but, if not, the reader is referred to the literature of the subject, 
especially A. C. Parker's book on the Iroquois Uses of Maize and Other Food Plants (Albany, r9ro).

One striking characteristic of the Indian maize-complex is its similarity throughout. It should be noted that our Indians were composed of many small groups independent politically and in many cases distinct as to language and most traits of culture as well. If we pass in review the successive tribal cultures from the Gulf to the St. Lawrence we shall encounter considerable diversity of traits, but throughout we shall find the maize-complex almost entire, particularly in all but its ceremonial elements. So far as our data go, the same varieties of corn, the same methods of planting, fertilizing, and cooking prevailed everywhere in the Mississippi Valley and eastward. It is difficult to account for this uniformity in one culture trait unless we assume that it was distributed from one place in its complete form. In that case each tribe would be relieved of the necessity for devising ways and means of utilizing maize and so make no important original contributions.

After having made an inventory of Indian maize culture it may be interesting to examine our own maize culture to see how completely our ancestors took over this aboriginal complex and to what extent it still survives. Our farmers formerly planted, and of ten yet plant, maize in hills; this was the universal Indian mode four to five grains being dropped at one place at regular intervals of about three feet, quite like a cornfield of today. In cultivation, the Indian hoed the earth up around the growing stalk, which is still the principle of the mechanical cultivator. For husking, our farmers use a husking pin, which, while now of iron, was not so very long ago of bone and wood, precisely like those still in use among our surviving eastern Indians. Ears of corn to be dried or preserved for seed often have their pendant husks braided together; this is typically Indian. The corn crib was used by the Indians and elevated on posts to keep the contents dry and to protect it from rodents. The type of crib which is larger at the top than at the bottom was also in use by the southern Indians.

The Indian planted beans and squashes among the corn. This has always been a favorite custom of our farmers. He also understood the art of testing his seed and of preparatory germination in 
warm water. Where fish were available they were used for fertilization, the rule being one fish to a hill.

The methods of cooking corn are, not only still about the same among us, but we also retain many of the Indian names for such dishes, as hominy and succotash. The famous roasting-ear in all its forms was known to the Indian. Then we must not forget the favorite mush, which is stirred with a wooden ladle strikingly like those of the Algonkin tribes. Some years ago our country people still made "lye hominy" with wood ashes, just as described by some early observers of the Indian.

Corn-husk mats may still be seen in some country homes. As I recall a few specimens examined, the technique was the same as the Iroquoian examples to be seen in our museums.

The one important innovation of the white man was the substitution of the mill for the mortar. Later, of course, came various kinds of machinery for the cultivation and gathering of corn, but all such machines are but mechanical appliances to perform more expeditiously the same old processes. It is clear that in pioneer days the white farmer took over the whole maize culture-complex entire, except its ceremonial and social elements. Even here we find some curious similarities. The husking-bee, which was one of the great social events of our fathers' times, is strikingly paralleled by an old Indian custom. No doubt if we knew more of the homely history of our forefathers we should find some surprising intrusions of ceremonial and superstitious practices to propitiate the growth of their crop.

If we reduce these data to a generalization, it appears that the white colonist took over the entire material complex of maize culture. He did not simply borrow the maize seed and then in conformity with his already established agricultural methods, or on original lines, develop a maize culture of his own. In fact, he has no basis for any claims to originality except in the development of mechanical appliances and the somewhat recent rationalization of agriculture by scientific investigation.

In this connection the maize culture of the Old World is particularly suggestive. At the discovery of America, samples of maize were carried home, seed was planted, and in a surprisingly 
short time its cultivation spread even so far as China; but the maize-complex of the Old World has scarcely anything in common with that of the Indian and the American farmer. The reason is plain-it was the isolated plant that came into European culture, necessitating original experimentations with the new seed, or, at least, the adaptation of its culture to the methods or "patterns" for the raising of other plants. The first American farmers, on the other hand, found themselves projected into the midst of a new culture, where it was much easier to adapt trait-complexes than to invent them. It is more than likely that we are here illustrating two characteristic modes of culture diffusion: in one case a new object or an isolated idea is carried far afield and dropped into the midst of a strange culture group, and in the other the group itself is dropped into the midst of a strange culture, or merely brought into contact with it. In the latter, whole complexes will be taken bodily; in the former, a new trait will be originally developed or simply adapted to some already existing pattern.

The taking over of the maize-complex by the whites has its parallels. One striking example is the tobacco-complex, where again the colonists took over all the essential parts of the traitcomplex. The manufacture of maple sugar is another. On the part of the Indians we have the taking over of the horse-complex of the Great Plains before the general assimilation of white culture began. Also, in the wide distribution of aboriginal traits we have presumptive evidence of intertribal borrowing, and the fact that distinct complexes like pottery making, coil basketry, acorn meal, soft buckskin tan, etc., are often found among many adjacent tribes without essential variations, indicates that one tribe after another took over these complexes entire in just the same way as our typical example of maize culture was taken over by the American colonists.

Returning to our discussion of maize culture, another suggestive fact is that the distribution of the American type of maize culture is the same now as in prehistoric times. In like manner, certain phases of Indian horse culture, which were derived from Spanish colonists and were somewhat different from those of the English colonists, still persist among the settlers of our Western states in 
contrast to those of the East. In general, students of the world's culture history have from time to time noted the tendency of specific culture traits to persist in one geographical locality regardless of racial and even linguistical change in the population. The preceding data suggest that the underlying condition of this is the observed tendency to take over entire culture-complexes instead of developing them from a single element. In other words, when a culture-complex once develops as an adjustment to a locality and works fairly well, it tends to persist in that locality and may prevail over complete changes in blood and language. It need not be the best adjustment of its kind, but it offers the practical advantage of immediate and certain return and, once adopted, inhibits other adjustments, however superior they may be.

This also has a bearing upon the much-discussed question of the geographical environment. If it appears that certain culturecomplexes have become localized and in a measure fixed, regardless of the coming and going of social groups of men, there must be some extra-human agency at work. Anthropologists recognize a number of aboriginal culture centers in North America, each of which at the period of exploration occupied a more or less definite geographical area. Although archaeological research has been far less systematic and extensive than the study of the historical Indian tribes, we have at hand a fair amount of data as to the prehistory of the historic culture centers. These data as they stand indicate that in such traits as leave archaeological traces most of the fundamental elements in the culture of a historic center took their origin in that locality. At least a distinct and independent form of prehistoric culture has not yet been found in the vicinity of these centers. Doubtless time will modify this view, but it is almost certain that the great age of each culture center will be demonstrated. In the light of the preceding discussion this may mean that the original elements in a type of culture began as adjustments to the locality in which the participating social group lived. When these adjustments worked, they were perpetuated. Other social groups drifted in, some hostile, some friendly, some no doubt related by blood and language, some not so related, but all finding it much easier to take up the adjustments of their hosts than to 
devise new ones. Since the blood of the group can be changed but slowly, its languages only somewhat less slowly, we may expect the course of time to eliminate any historical correlations that may have once held between blood, language, and culture. The term culture as used by anthropologists generally includes such groups of traits as social organization, ceremonial activities, art, and material culture. Of these, it appears that social organization is less readily changed in contrast to the last. It is the food, shelter, and transportation complexes of material culture that the intruding group will take over bodily. Then the chances are that one by one the associated ceremonies always found intimately connected with food production will be taken over to displace those now made useless and ultimately drag in their social counterparts. Even a superficial review of the data so far accumulated by anthropologists will show how well this hypothetical picture fits the facts for the several culture centers.

Now it is clear that the objective condition contributing to this result is the stable geographical environment, chiefly the climate, fauna, and flora. We may conclude, therefore, that one of the important factors accounting for the lack of correlations between the somatic types, languages, and cultures of our North American Indian tribes is to be sought in the objective environment. It should be noted, however, that in this case the environment is not a formative factor but only a perpetuator. The formative factors are to be sought in the initial social groups. While these observations are based upon concrete facts in North American primitive culture, it is highly probable that they will hold for other parts of the world. 